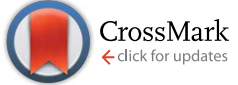

Cite this: RSC Adv., 2017, 7, 9500
Received 17th October 2016 Accepted 22nd January 2017 DOI: 10.1039/c6ra25355e rsc.li/rsc-advances

\section{Synthesis and investigation of a self-assembled hydrogel based on hydroxyethyl cellulose and its in vitro ibuprofen drug release characteristics}

\begin{abstract}
Nan Sun, ${ }^{a}$ Ting Wang ${ }^{* a b}$ and Xiufeng Yan ${ }^{b}$
Self-assembled cellulose-based hydrogels are a new type of supramolecular architecture with potential in biomedical applications. By our preparation, hydrophobic lauryl side-chains were grafted onto hydroxyethyl cellulose (HEC- $\mathrm{C}_{12}$ ) and ibuprofen molecules were encapsulated and solubilized by poly( $\beta$-cyclodextrin) ( $\beta$ $\mathrm{CDP} / \mathrm{BBU})$. The content of active residual cavities in $\beta$-CDP with inclusion abilities in $\beta$-CDP/IBU was determined to be $31.3 \mathrm{wt} \%$ by the phenolphthalein probe method, then the residual cavities were used to spontaneously form a self-assembled hydrogel (gel-( $\beta) C D P-H E C / I B U)$ in water with the hydrophobic $\mathrm{C}_{12}$ side-chains on HEC- $C_{12}$. The critical concentrations of $\mathrm{HEC}-\mathrm{C}_{12}$ and $\beta-C D P / I B U$ in the selfassembled hydrogel were fixed at $30 \mathrm{mg} \mathrm{mL}^{-1}$ and $35 \mathrm{mg} \mathrm{mL}^{-1}$ respectively, as shown by the dynamic viscosity results. The synthesized macromolecules and hydrogels were characterized by proton nuclear magnetic resonance $\left({ }^{1} \mathrm{H}\right.$ NMR) and Fourier transform infrared (FTIR) spectroscopy, Scanning Electron Microscopy (SEM), Gel Permeation Chromatography (GPC) and powder X-ray diffractometry (PXRD). A swelling study and the in vitro drug release characteristics of IBU in gel-( $\beta) C D P-H E C / I B U$ were investigated. The results showed that the loaded content of IBU in gel-( $\beta) C D P-H E C / I B U$ was 5 wt $\%$, and that IBU encapsulated in gel-( $\beta$ )CDP-HEC/IBU presented sustained release characteristics over $1440 \mathrm{~min}$. In addition, the Korsmeyer-Peppas kinetic model gave a better correlation for the release of IBU, and the release procedure was a non-Fickian diffusion process.
\end{abstract}

\section{Introduction}

Hydrogels are a kind of three-dimensional network which consists of covalently crosslinked hydrophilic polymers, and may absorb many times their dry weight of water without being dissolved. ${ }^{1-3}$ In recent years, hydrogels have been widely studied due to their promising applications in cosmetics, biomaterials, drug delivery systems, wastewater purification, and so on. ${ }^{\text {4-10 }}$ Among them, considerable research attention has been focused on CD-based hydrogels. As we know, CDs are non-reducing cyclic maltooligosaccharides produced from starch by cyclodextrin glycosyltransferase and are composed of hydrophilic outer surfaces and hydrophobic inner cavities. ${ }^{11-16}$ This structure with its remarkable abilities can form inclusion complexes with a wide range of guest moieties and hydrophobic side chains, ${ }^{17-23}$ which is a supramolecular interaction without covalent bonds. Therefore, CD-based hydrogels have become one of the most widely studied functional hydrogels in the field

${ }^{a}$ Department of Chemistry, College of Science, Northeast Forestry University, Harbin 150040, P. R. China. E-mail: thundersking@aliyun.com

${ }^{b}$ Alkali Soil Natural Environmental Science Center, Northeast Forestry University, Key Laboratory of Saline-alkali Vegetation Ecology Restoration in Oil Field, Ministry of Education, Harbin 150040, P. R. China of self-assembly, ${ }^{24,25}$ especially in biomedical and pharmaceutical fields. ${ }^{5,26-29}$

In many application fields, ordinarily traditional gels are based on organic synthetic polymers, such as poly(acrylamide), poly(2-hydroxyethylacrylate), poly(2-hydroxymethylacrylamide), poly(hydroxyethyl methacrylate) and so on. ${ }^{30-32}$ Synthetic polymers are non-biodegradable, and the commercialization of these organic synthetic polymer gels is usually limited by the fact that the preparation of the polymer matrices requires large amounts of potentially toxic organic solvents, which are often not able to meet the severe requirements of applications in drug delivery, bio-pharmaceuticals and so on. Herein, HEC, which is a kind of non-ionic cellulose ether with good water solubility and can be easily manufactured using natural cellulose as a raw material, is used as the hydrogel matrix, instead of synthetic polymers, taking advantage of cellulose resources, including its renewable nature, biocompatibility and biodegradability. ${ }^{33-35}$ To our knowledge, no studies have been performed on the formation of self-assembled supramolecular hydrogels between hydrophobically modified HEC and $\beta$-CDP.

Ibuprofen, a non-steroidal anti-inflammatory drug, is usually formulated into many topical preparations to reduce the adverse side effects and avoid hepatic first-pass metabolism. But it is difficult to maintain effective concentrations by topical delivery due to its poor skin permeation ability. ${ }^{36}$ So far, 
hydrogel matrices such as carbomer $940,{ }^{37}$ xanthan gum, ${ }^{38,39}$ carrageenan, $^{37}$ dextran $^{22}$ and cellulose ${ }^{40}$ have been used to increase the viscosity of hydrogels for the topical application of IBU. ${ }^{37}$ However, there are few reports that utilize self-assembly methods to prepare IBU hydrogels, especially CD based hydrogels. Owing to its simple preparation using the technique of self-assembly and the intrinsic advantages for drug delivery from CD, the loading of IBU by CD in a hydrogel through the technique of self-assembly is no doubt a desirable subject of study, whether in theory or in practice. In that case, the purpose of this study is to focus on the synthesis of a self-assembled IBUloaded hydrogel based on CDs and HEC. According to the literature, IBU is a functional molecule that is efficacious in restraining soft-tissue pain and osteoarthritis. However, the hydrophobic properties of IBU restrain its distribution in hydrogels, which decreases the bioavailability in medical applications. Therefore the solubility of IBU was enhanced through formation of inclusion complexes with $\beta$-CDP. First, HEC-C $_{12}$ and $\beta$-CDP were synthesized in a controlled manner. Then, IBU was encapsulated by $\beta$-CDP and the content of active residual cavities in $\beta$-CDP in $\beta$-CDP/IBU was determined. After that, the HEC based gel-( $\beta$ )CDP-HEC/IBU was obtained just in aqueous solution due to the self-assembly process between the $\mathrm{C}_{12}$ side-chains and the residual hydrophobic cavities of $\beta$-CDP, with the IBU drug encapsulated in $\beta$-CDP, as mentioned previously. Hence, the synthesized novel gel-( $\beta)$ CDP-HEC/IBU was a safe, nonirritating, biocompatible and biodegradable hydrogel for biomedical applications. Subsequently, the IBU-loading content, swelling and the in vitro release characteristics were evaluated.

\section{Experimental}

\section{Materials}

HEC (720 $000 \mathrm{~g} \mathrm{~mol}^{-1}$, DS $\left.=1.0-1.2, \mathrm{MS}=2.5\right)$ was purchased from Sigma-Aldrich Co., Ltd., USA. $\beta$-CD (1135 $\left.\mathrm{g} \mathrm{mol}^{-1},>98 \%\right)$, IBU (206.28 $\mathrm{g} \mathrm{mol}^{-1},>98 \%$ ), 1-chlorododecane $\left(\mathrm{C}_{12}, \mathrm{AR}\right)$, EPI (AR) and phenolphthalein (AR) were obtained from Aladdin Industrial Co., Ltd., China. N,N-Dimethylacetamide (DMAc, $\mathrm{AR}$ ), lithium chloride ( $\mathrm{LiCl}, \mathrm{AR}$ ), pyridine (AR) and sodium hydroxide $(\mathrm{NaOH}, \mathrm{AR})$ were supplied by Kermel Chemical Reagent Co., Ltd., China. Other reagents were used without further purification.

\section{Preparation of HEC- $\mathrm{C}_{12}$}

HEC-C $_{12}$ was synthesized using a Williamson etherification reaction. $^{22} 2 \mathrm{~g}$ of HEC was added to $80 \mathrm{~mL}$ of DMAc $(2 \mathrm{~g}$ of $\mathrm{LiCl}$ was mixed in for solubilization) at $80{ }^{\circ} \mathrm{C}$, and the mixture was dissolved under continuous mechanical stirring for $24 \mathrm{~h}$. Then $0.68 \mathrm{~mL}$ of pyridine and $2 \mathrm{~mL}$ of 1 -chlorododecane were added to the HEC solution successively. After $8 \mathrm{~h}$ of stirring at $80{ }^{\circ} \mathrm{C}$, the solution was cooled to room temperature. Subsequently, it was poured into a dialysis bag (MWCO 8-12 kDa, Biosharp, USA) and dialyzed for 7 days. Finally, the products were obtained by freeze drying.

\section{Preparation of $\beta$-CDP}

$\beta$-CDP was synthesized by reaction of $\beta$-CD with EPI in alkaline environment. ${ }^{41-44}$ First, $10 \mathrm{~g}$ of $\beta$-CD was dissolved in $15 \mathrm{~mL}$ of $15 \mathrm{wt} \% \mathrm{NaOH}$ by stirring overnight at room temperature. Then the mixture was heated to $35^{\circ} \mathrm{C}$ and $7 \mathrm{~mL}$ of EPI was added in a 1 : $10 \beta$-CD : EPI molar ratio. After $200 \mathrm{~min}$, the mixture was poured into a dialysis bag (MWCO 8-12 kDa, Biosharp, USA) and dialyzed for 7 days. Finally, the products were obtained by freeze drying.

\section{Solubilization of IBU by $\beta$-CDP}

The hydrophobic IBU molecules were encapsulated in the selfassembled hydrogel by formation of inclusion complexes with $\beta$-CDP before mixing with HEC- $\mathrm{C}_{12}$, and the solubility of IBU could be enhanced in this way at the same time. Phase solubility studies were carried out in water at room temperature according to the method described by Higuchi and Connors. ${ }^{45}$ An excess amount of IBU was mixed with aqueous solutions containing increasing amounts of $\beta$-CDP. The suspensions were stirred at room temperature for $24 \mathrm{~h}$ to reach equilibrium. Then the solutions were filtered and the filtrate was lyophilized to obtain the synthesized $\beta$-CDP/IBU. The concentration of IBU in solution was determined using a UV spectrophotometer (TU1901, Persee, China) at a wavelength of $219 \mathrm{~nm}$ according to the calibration curve of IBU. The solubility of IBU in the $\beta$-CDP solution was calculated and the phase-solubility diagram for the solubility of IBU versus concentration of $\beta$-CDP was plotted. All experiments were performed in triplicate. ${ }^{46}$ The apparent stability constant $\left(K_{1: m}\right)$ can be determined from the phasesolubility diagrams.

\section{Determination of active residual cavities of $\beta$-CDP in $\beta-C D P /$ IBU}

The content of active residual cavities in $\beta$-CDP with inclusion abilities in $\beta$-CDP/IBU can be determined by the phenolphthalein probe method, as our previous work mentioned. ${ }^{\mathbf{4 7 4 8}}$ For determination, $0.02 \mathrm{~g}$ of dried $\beta$-CDP/IBU was dissolved in $5 \mathrm{~mL}$ of $10^{-3} \mathrm{~mol} \mathrm{~L}^{-1}$ phenolphthalein in a $50 \mathrm{~mL}$ comparison tube and then $15 \mathrm{~mL}$ of a $\mathrm{Na}_{2} \mathrm{CO}_{3}-\mathrm{NaHCO}_{3}$ buffer solution $(\mathrm{pH}=$ 10.5) was added. The mixed solution was kept in the dark and stirred for $12 \mathrm{~h}$ for complete inclusion equilibrium. After that, the solution was transferred to a $200 \mathrm{~mL}$ volumetric flask, and diluted with a $\mathrm{Na}_{2} \mathrm{CO}_{3}-\mathrm{NaHCO}_{3}$ buffer solution $(\mathrm{pH}=10.5)$ to volume. Then the content of active residual cavities in $\beta$-CDP in $\beta$-CDP/IBU was determined using a UV spectrophotometer (TU1901, Persee, China) at a wavelength of $553 \mathrm{~nm}$.

\section{Preparation of gel-( $\boldsymbol{\beta}) \mathrm{CDP}-\mathrm{HEC} / \mathrm{IBU}$}

The residual hydrophobic cavities of $\beta$-CDP in $\beta$-CDP/IBU can encapsulate hydrophobic $\mathrm{C}_{12}$ side-chains due to host-guest interactions. Gel-( $\beta$ CDP-HEC/IBU was prepared by mixing equal volumes of aqueous solutions of $\beta$-CDP/IBU $\left(0 \mathrm{mg} \mathrm{mL} \mathrm{m}^{-1}\right.$ to $\left.50 \mathrm{mg} \mathrm{mL}^{-1}\right)$ and HEC-C ${ }_{12}\left(5 \mathrm{mg} \mathrm{mL}^{-1}\right.$ to $\left.40 \mathrm{mg} \mathrm{mL}^{-1}\right)$. Each sample was obtained by vigorously stirring at room temperature for 3 days so that $\beta$-CDP could encapsulate the $\mathrm{C}_{12}$ side-chains 
thoroughly. Then the dynamic viscosities $(\eta)$ of the obtained samples were measured using a NDJ-1 rotary viscometer (Jingke, China) at $25 \pm 0.01{ }^{\circ} \mathrm{C}$, and the optimum concentrations of $\beta$-CDP/IBU and HEC- $\mathrm{C}_{12}$ for preparing gel- $(\beta) \mathrm{CDP}-\mathrm{HEC} /$ IBU were proposed accordingly. The hydrogels were repeatedly centrifuged (10 $000 \mathrm{rpm}, 15 \mathrm{~min}$ ) and washed with $5 \mathrm{~mL}$ of distilled water 3 times. After that, gel-( $\beta$ )CDP-HEC/IBU was freeze-dried.

\section{Characterization}

${ }^{1} \mathbf{H}$ NMR. The structural properties of HEC, HEC-C ${ }_{12}$, IBU, $\beta$ CDP and gel-( $\beta$ CDP-HEC/IBU were also characterized using ${ }^{1} \mathrm{H}$ NMR spectroscopy. It was performed using a $400 \mathrm{MHz}$ Bruker Avance III HD 400 (Bruker, Germany) spectrometer at room temperature, using tetramethylsilane and DMSO- $_{6}$ as the internal standard and solvent, respectively.

FTIR. The structural properties of HEC, HEC-C ${ }_{12}, \beta-\mathrm{CD}, \beta-$ CDP, IBU and gel-( $\beta$ )CDP-HEC/IBU were characterized by FTIR spectroscopy. It were performed using potassium bromide pellets and recorded using a Nicolet IS10 spectrometer (Thermo Fisher Scientific, USA), with a wavenumber range from 4000$400 \mathrm{~cm}^{-1}$ and a resolution of $4 \mathrm{~cm}^{-1}$ for 32 scans.

GPC. The molecular weight distributions of the synthesized water soluble $\beta$-CDP were determined using GPC on a connecting GPC column: TSK gel G4000PWXL (TOSOH, Tokyo, Japan). Milli-Q water was selected as the mobile phase, and the flow rate was set at $0.5 \mathrm{~mL} \mathrm{~min}^{-1}$. Molecular weight calculation software was connected to the HPLC integration system (Shimadzu LC$10 \mathrm{AD}$, Kyoto, Japan). GPC peaks were detected with a refractive index detector (Waters 410, Milford, MA, USA) and polyethylene oxide/glycol easivials were chosen as the standard substance.

SEM. The surface morphologies of the synthesized HEC, HEC-C $_{12}, \beta-\mathrm{CD}, \beta$-CDP, IBU, $\beta$-CDP/IBU and gel-( $\left.\beta\right) \mathrm{CDP}-\mathrm{HEC} /$ IBU were characterized by SEM. Micrographs were obtained using JSM-7500F (JEOL, Japan) equipment with an acceleration voltage of $15 \mathrm{kV}$ and the sample was coated with a thin layer of gold before observation.

PXRD. The PXRD patterns for IBU, $\beta$-CDP/IBU and gel- $(\beta)$ CDP-HEC/IBU were recorded using an X'Pert3 Powder X-ray diffractometer (PANalytical, Netherlands) with monochromatic $\mathrm{Cu}-\mathrm{K} \alpha$ radiation $(\lambda=1.540598 \AA)$. The voltage and current were $40 \mathrm{kV}$ and $40 \mathrm{~mA}$. The $2 \theta$ range was $5^{\circ}$ to $90^{\circ}$ in steps of $0.013^{\circ}$ with a count time of $100 \mathrm{~s}$.

Freeze drying. The synthesized products were all freeze-dried for $24 \mathrm{~h}$ to obtain dried samples using a SJIA-10N freezer dryer (Shuangjia, China). The characterization of the final product gel-( $\beta) \mathrm{CDP}-\mathrm{HEC} / \mathrm{IBU}$ was performed in the xerogel state.

\section{Swelling and IBU in vitro release studies}

Swelling studies of gel-( $\beta$ )CDP-HEC/IBU were carried out by a gravimetric method. A dry hydrogel sample was weighed (recorded as $W_{\mathrm{d}}(\mathrm{g})$ ) and allowed to swell in phosphate-buffered saline buffer solution (PBS, $0.1 \mathrm{mmol} \mathrm{L}^{-1}, \mathrm{pH}=7.4$ ) at $37^{\circ} \mathrm{C}^{49}$ At different time intervals, the swelling hydrogel was removed from the aqueous solution and its surface was dried with a filter paper, the weight was measured as $W_{\mathrm{s}}(\mathrm{g})$. The swelling ratio (SR) of the hydrogel at different time intervals is determined using eqn (1) $)^{50}$ and the values of SR were measured and calculated in triplicate.

$$
\mathrm{SR}=\frac{\left(W_{\mathrm{s}}-W_{\mathrm{d}}\right)}{W_{\mathrm{d}}}
$$

In vitro release of IBU was carried out using a dialysis bag diffusion technique. ${ }^{51-53}$ PBS buffer solution $\left(0.1 \mathrm{mmol} \mathrm{L}^{-1}, \mathrm{pH}\right.$ 7.4) was used as the release medium..$^{54}$ For the release experiment, a control group $\mathrm{HEC}_{12}$ - $\mathrm{IBU}_{1}$ was synthesized by dissolving $0.5 \mathrm{~g}$ of $\mathrm{HEC}^{-\mathrm{C}_{12}}$ in a mixed solution of $20 \mathrm{~mL}$ of water and $20 \mathrm{~mL}$ of $250 \mathrm{mg} \mathrm{L}^{-1}$ IBU ethanol solution. The obtained HEC-C $_{12} /$ IBU was freeze-dried to get a dry product. After that, $0.1 \mathrm{~g}$ of gel-( $\beta$ )CDP-HEC/IBU and HEC- $\mathrm{C}_{12} /$ IBU were dissolved in $20 \mathrm{~mL}$ of distilled water, separately. Each solution was transferred to a dialysis bag (MWCO 12-14 kDa, Biosharp, USA) with the two ends fixed by clips and then placed in a preheated release medium $(50 \mathrm{~mL})$ at $37{ }^{\circ} \mathrm{C}$ under moderate stirring. At different time intervals, $1 \mathrm{~mL}$ of the external medium was withdrawn and then an equal volume of fresh medium was added.

\section{Kinetic study of swelling and IBU release}

Based on the relative rate of diffusion of water into the hydrogel matrix and the rate of polymer chain relaxation, the swelling of the polymers and the IBU release profile from gel-( $\beta$ )CDP-HEC/ IBU could be simulated by four kinetic models, ${ }^{55-57}$ the models are listed below.

The zero order kinetic model:

$$
\frac{M_{t}}{M_{\infty}}=k_{0} t+C_{0}
$$

The first order kinetic model:

$$
\ln \left(1-\frac{M_{t}}{M_{\infty}}\right)=-k_{1} t+C_{1}
$$

The Higuchi kinetic model is widely used to describe the empirical process of drug delivery, which complies with Fick's law and can be expressed as: ${ }^{58}$

$$
\frac{M_{t}}{M_{\infty}}=k_{\mathrm{H}} t^{\frac{1}{2}}+C_{\mathrm{H}}
$$

The Korsmeyer and Peppas kinetic model described the first $60 \mathrm{wt} \%$ of the release behavior of a hypothetical distribution, and it attempts to explain release mechanisms where erosion and/or dissolution of the matrix occurs and is represented as follows: ${ }^{59,60}$

$$
\frac{M_{t}}{M_{\infty}}=k_{\mathrm{KP}} t^{n}
$$

where $M_{t} / M_{\infty}$ is the cumulative release efficiency of IBU in a time interval $t(\min ), k_{0}\left(\min ^{-1}\right), k_{1}\left(\min ^{-1}\right), k_{\mathrm{H}}\left(\min ^{-1 / 2}\right)$, and 
$k_{\mathrm{KP}}\left(\min ^{-n}\right)$ are the constant release rates of the four kinetic models, respectively, $C_{0}, C_{1}$, and $C_{\mathrm{H}}$ are the intercepts of eqn (2) to (4), respectively, and $n$ is an exponent that indicates the mechanism by which the drug release process occurs. When the value of $n$ is equal to 0.5 , drug release occurs through a diffusion phenomenon, Fickian type. When the value of $n$ is between 0.5 and 1 , drug release is caused by a non-Fickian mechanism or anomalous diffusion, and when the value of $n$ equals 1 , the mechanism of drug release depends on the process of relaxation of the polymer chains..$^{55,61}$

\section{Results and discussion}

\section{Characterization of HEC- $\mathrm{C}_{12}$}

The hydrophobic $\mathrm{C}_{12}$ side-chains are grafted onto HEC using a Williamson etherification reaction, and the grafting of the $\mathrm{C}_{12}$ side-chains on HEC was characterized using ${ }^{1} \mathrm{H}$ NMR, FTIR and SEM.

${ }^{1} \mathbf{H}$ NMR analysis. In order to determine the degree of substitution of $\mathrm{C}_{12},{ }^{1} \mathrm{H}$ NMR spectroscopy of HEC and HEC-C ${ }_{12}$ was performed and illustrated in Fig. $1 \mathrm{a}$ and $\mathrm{b}$, respectively. The signals at $\delta 1.24 \mathrm{ppm}$ and $0.86 \mathrm{ppm}$ in Fig. 1b, which are attributed to the $\mathrm{CH}_{2}$ and $\mathrm{CH}_{3}$ protons of the long-chain alkyl group in $\mathrm{HEC}_{-\mathrm{C}_{12}}$, are not observed in Fig. 1a. The ${ }^{1} \mathrm{H}$ signals of the glucose units of HEC are distributed in the range of $\delta 3.23-$ $3.74 \mathrm{ppm}$. By integration of the peak ratio, the degree of substitution of $\mathrm{C}_{12}$ on $\mathrm{HEC}$ is calculated to be $4 \%$ of the glucose units according to the amount of $\mathrm{C}_{12}$ side-chains introduced in the reaction mixture.

FTIR analysis. Fig. $2 \mathrm{a}$ and $\mathrm{b}$ are the FTIR spectra of HEC and HEC-C $_{12}$, respectively. In comparison to Fig. 2a, the strong bands at 2924 and $2874 \mathrm{~cm}^{-1}$ in Fig. $2 \mathrm{~b}$, which are attributed to the stretching vibrations of saturated $\mathrm{C}-\mathrm{H}$, are obviously enhanced. This phenomenon demonstrates that the product of

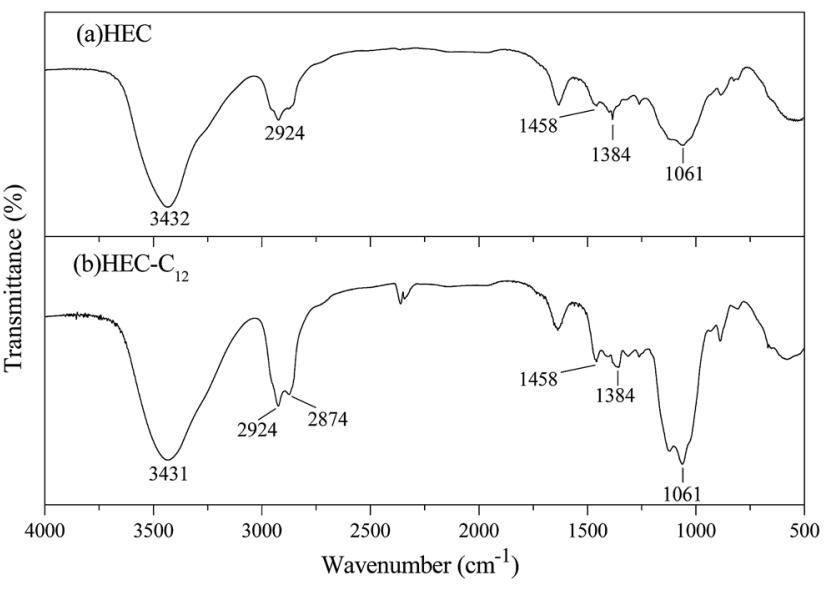

Fig. 2 FTIR spectra of HEC (a) and HEC-C 12 (b).

HEC-C $_{12}$ has more hydrophobic saturated $\mathrm{C}-\mathrm{H}$ groups than HEC. Furthermore, the band at $1061 \mathrm{~cm}^{-1}$, which is due to the stretching vibration of ether $\mathrm{C}-\mathrm{O}$, is also enhanced. This result proves that the increase in saturated $\mathrm{C}-\mathrm{H}$ groups results from the Williamson etherification reaction.

SEM analysis. The surface morphology of HEC and HEC- $\mathrm{C}_{12}$ recorded using SEM is shown in Fig. $3 a$ and b, respectively. The SEM image of HEC (Fig. 3a) shows a compact thin colloidal structure, while that of HEC-C $_{12}$ (Fig. 3b) shows a porous surface with a dendritic structure on the side. This indicates that the introduction of $\mathrm{C}_{12}$ changes the apparent appearance of HEC.

\section{Characterization of $\boldsymbol{\beta}$-CDP}

GPC analysis. $\beta$-CDP was crosslinked by EPI in $15 \mathrm{wt} \% \mathrm{NaOH}$ aqueous solution, and GPC was used to test the molecular weight distribution of the synthesized $\beta$-CDP. The retention
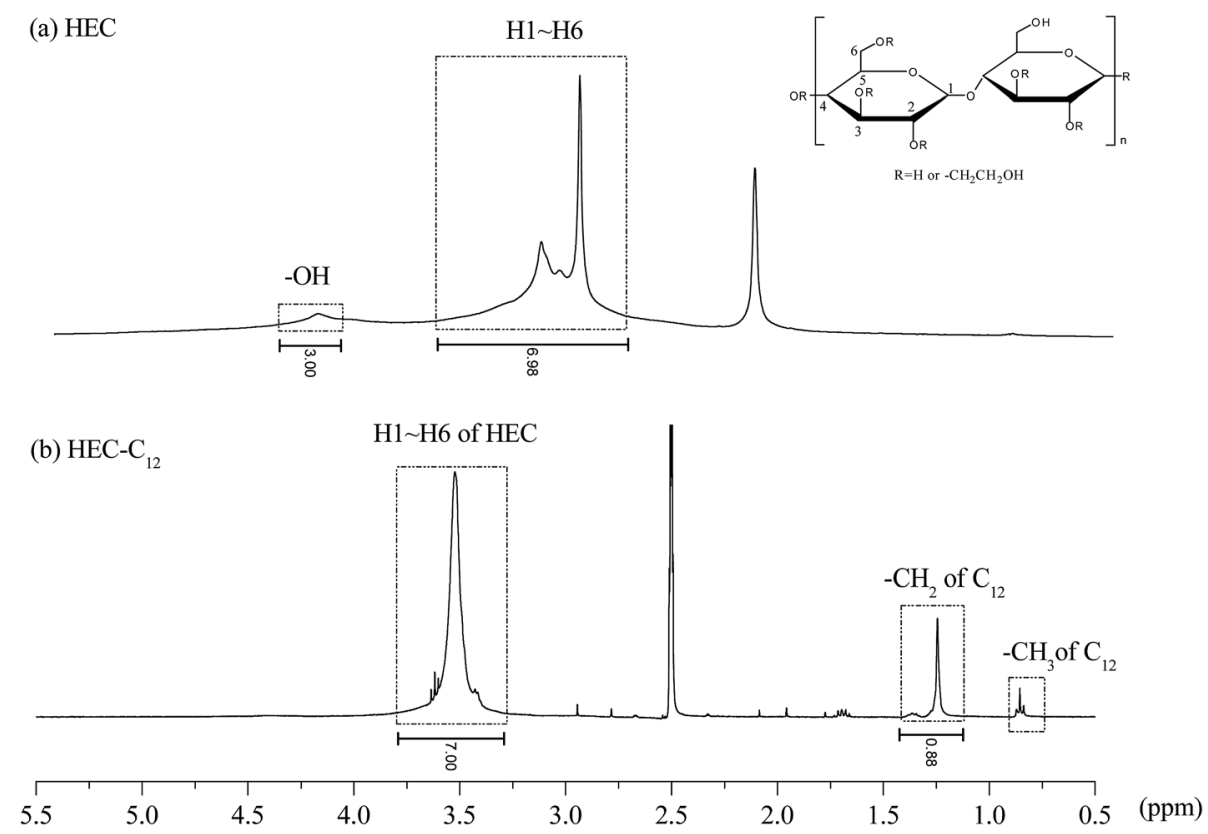

Fig. $1{ }^{1} \mathrm{H}$ NMR spectra of HEC (a) and HEC- $\mathrm{C}_{12}$ (b) recorded at $400 \mathrm{MHz}$ in DMSO- $\mathrm{d}_{6}$ at room temperature. 

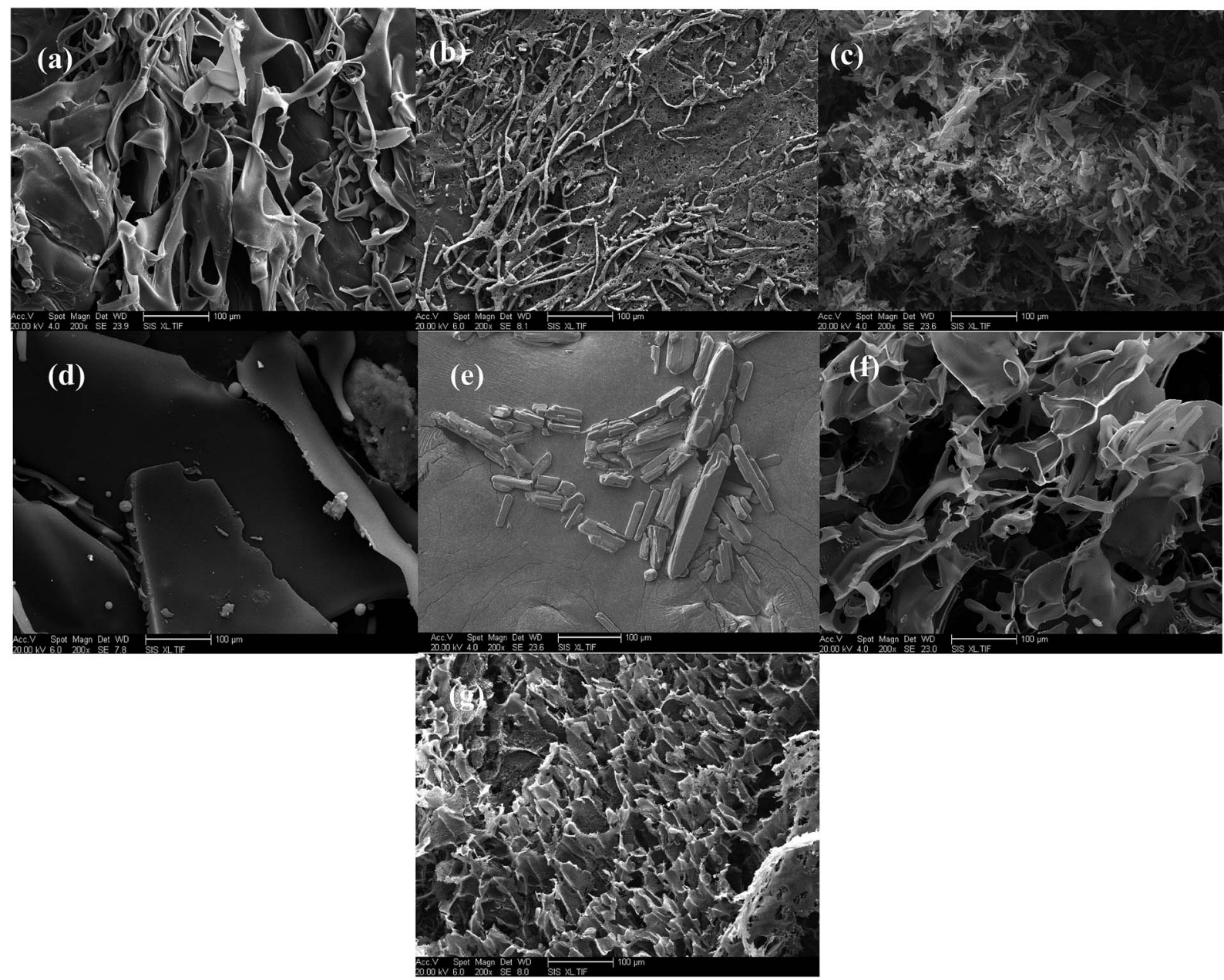

Fig. 3 The SEM images of HEC ( $\times 200)(a), H E C-C_{12}(\times 200)(b), \beta-C D(\times 200)(c), \beta-C D P(d), I B U(\times 200)(e), \beta-C D P / I B U(\times 200)(f)$ and gel-( $\left.\beta\right)$ CDP-HEC/IBU $(\times 200)(g)$.

time $\left(t_{\mathrm{R}}\right)$ and the weight-average molecular weight $\left(M_{\mathrm{w}}\right)$ were determined to be $11.484 \mathrm{~min}$ and $1731.1 \mathrm{kDa}$, respectively, as shown in Fig. 4. The results demonstrate that the degree of

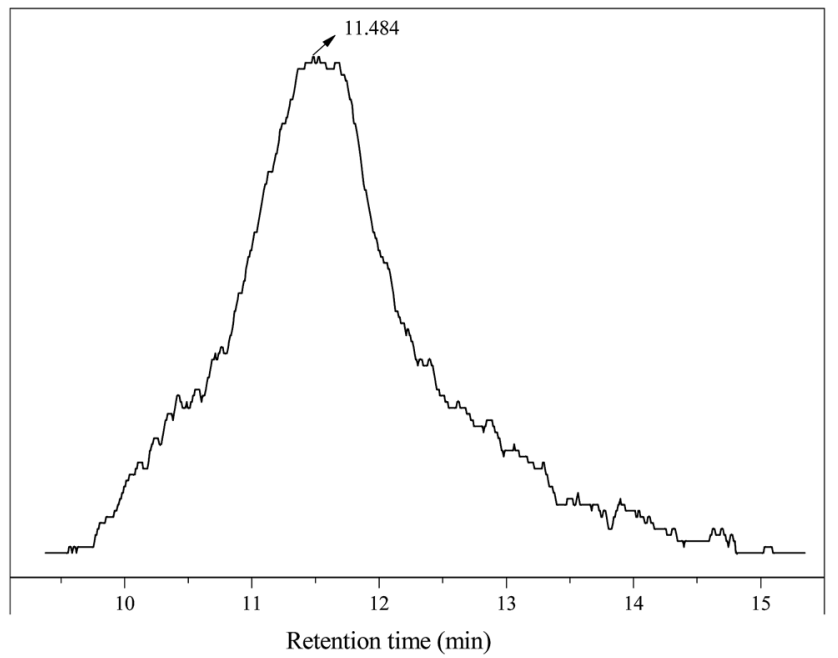

Fig. 4 GPC analysis of $\beta$-CDP polymerization of $\beta$-CDP is around 1500. According to the research of Renard and Koopmans, ${ }^{42,43}$ an almost linear copolymer of $\beta$-CDP with a suitable degree of polymerization is obtained by carefully controlling the synthesis conditions in order to obtain high water solubility and excellent encapsulation activity.

FTIR analysis. FTIR spectra of $\beta$-CD and $\beta$-CDP are shown in Fig. $5 \mathrm{a}$ and $\mathrm{b}$, respectively. Comparing Fig. $5 \mathrm{a}$ with $5 \mathrm{~b}$, the band at $3397 \mathrm{~cm}^{-1}$, corresponding to $\mathrm{O}-\mathrm{H}$ stretching vibrations, is blue shifted to $3423 \mathrm{~cm}^{-1}$, which is attributed to the breaking of hydrogen bonds resulting from the polymerization of $\beta$-CD. In addition, the $\mathrm{O}-\mathrm{H}$ in-plane bending vibration and out-of-plane bending vibration at $1654 \mathrm{~cm}^{-1}, 707 \mathrm{~cm}^{-1}$ and $756 \mathrm{~cm}^{-1}$ in Fig. $5 \mathrm{~b}$ are decreased compared to those of Fig. $5 \mathrm{a}$, while the $\mathrm{C}-\mathrm{O}-\mathrm{C}$ stretching vibrations at 1034 and $1084 \mathrm{~cm}^{-1}$ are increased, in contrast. These phenomena are due to the breaking and rearrangement of hydrogen bonds during the polymerization process.

SEM analysis. The SEM image of $\beta$-CD shown in Fig. 3c shows petal shaped debris, while after polymerization, the synthesized $\beta$-CDP in Fig. 3d exhibits a compact layered 


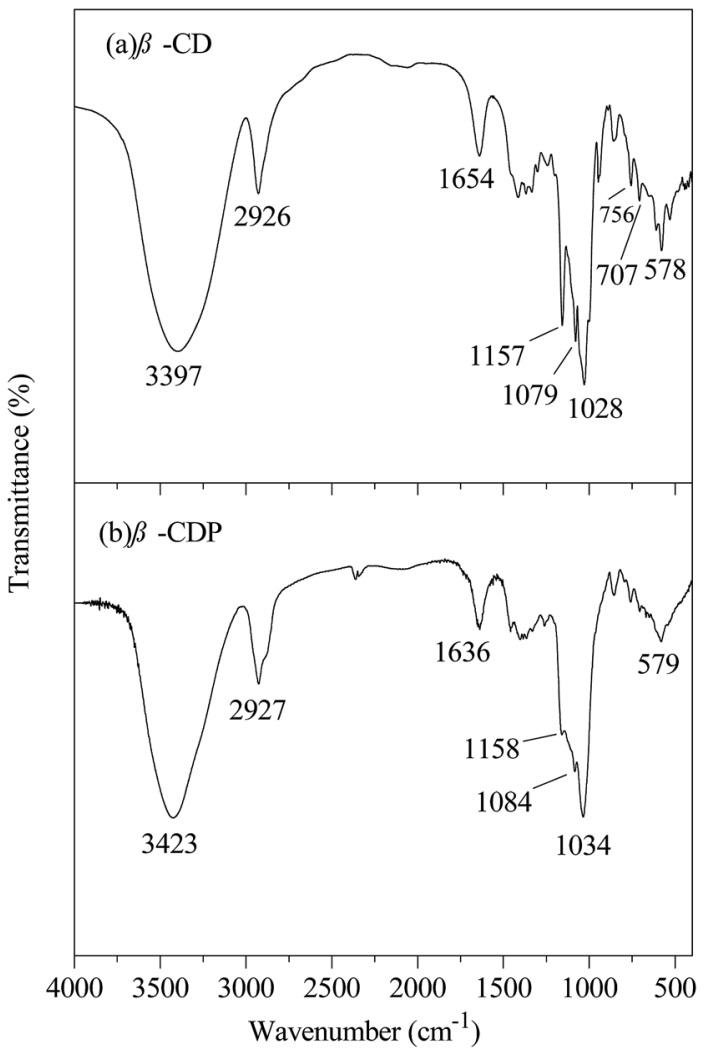

Fig. 5 FTIR spectra of $\beta-C D(a)$ and $\beta-C D P(b)$.

morphology with a colloidal surface. This is due to the crosslinking together of $\beta$-CD molecules by EPI, resulting in a different surface morphology compared to pure $\beta$-CD. The active hydrophobic cavities in the synthesized $\beta$-CDP/IBU provide binding sites which can associate with the $\mathrm{C}_{12}$ sidechains, also the polymer chains of $\beta$ - $\mathrm{CDP} / \mathrm{IBU}$ and the macromolecule chains of HEC- $\mathrm{C}_{12}$ can interpenetrate with each other, leading to an enhancement of mechanical strength for gel-( $(\beta)$ CDP-HEC/IBU.

\section{Phase solubility studies}

Phase-solubility diagrams are widely used for studying hydrophobic drug/CD complexes because they provide information on both the solubilizing ability of CDs and the apparent stability constants of the inclusion complexes. ${ }^{45,62,63}$ The solubilized IBU concentration was calculated according to the calibration curve of IBU, which is established as seen in eqn (6), with a correction coefficient $\left(R^{2}\right)$ of 0.9986 :

$$
A=6394.68 c_{\mathrm{IBU}}+0.723
$$

where $A$ denotes the absorbance of the diluted IBU, and $c_{\mathrm{IBU}}$ represents the concentration of the diluted IBU $\left(\mathrm{mol} \mathrm{L}^{-1}\right)$.

From Fig. 6, it can be seen that the concentration of solubilized IBU linearly increased with the concentration of $\beta$-CDP $\left(R^{2}=0.998\right)$. This relationship could be defined as the classic $\mathrm{A}_{\mathrm{L}}$-type of Higuchi, ${ }^{45}$ where an A-type curve indicates the formation of a soluble complex and $A_{\mathrm{L}}$-type indicates a linear

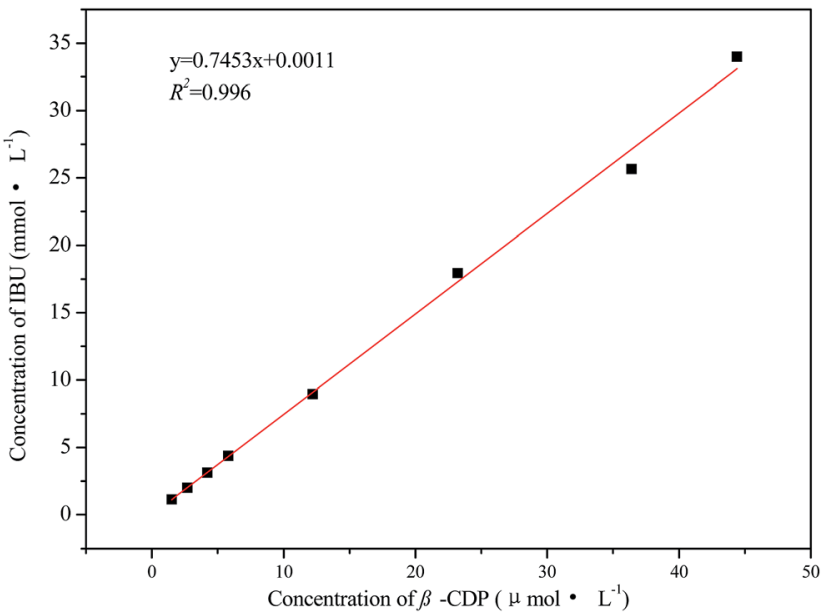

Fig. 6 Phase-solubility diagram of IBU in aqueous solutions of $\beta$-CDP.

increase in solubility. The result demonstrates that an inclusion complex with the molar ratio $1: 1$ between IBU molecules and $\beta$-CDP formed, and the apparent stability constant $K_{1: 1}$ (L $\mathrm{mmol}^{-1}$ ) can be calculated from the phase-solubility diagram according to eqn (7):

$$
K_{1: 1}=\frac{\text { slope }}{S_{0}(1-\text { slope })}
$$

where the slope is the value given by the linear regression, and $S_{0}$ is the solubility of IBU in the absence of $\beta$-CDP in aqueous solution, which is also given by the linear regression $\left(\mathrm{mmol} \mathrm{L}^{-1}\right)$.

The $K_{1: 1}$ value for $\beta$-CDP/IBU is found to be $2660 \mathrm{~L} \mathrm{mmol}^{-1}$ at room temperature. With an increasing concentration of $\beta$ CDP, the water solubility of IBU becomes much higher than its original values. Thus, $\beta$-CDP could significantly improve the water solubility of IBU, and $1.50 \mathrm{~g}$ of $\beta$-CDP was used to solubilize $0.17 \mathrm{~g}$ of IBU in $30 \mathrm{~mL}$ of distilled water here to form $\beta$ -

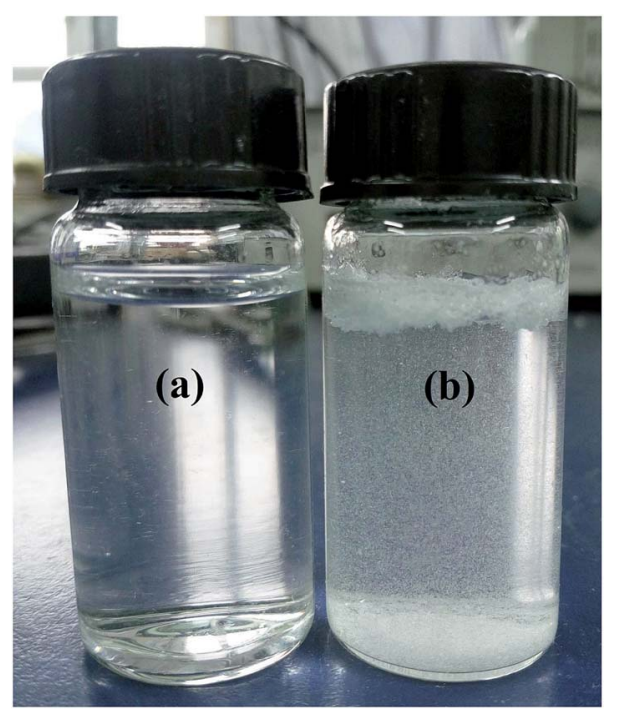

Fig. 7 The IBU solubilized by $\beta-C D P(a)$ and its control group without the addition of $\beta$-CDP (b). 
CDP/IBU inclusion complexes. The physical maps of the solubilized IBU and its control group without the addition of $\beta$-CDP are shown in Fig. 7a and b, respectively.

\section{Inclusion ability of the active residual cavities of $\beta$-CDP in

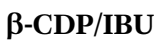

As mentioned above, IBU molecules can be encapsulated into the cavities contained in $\beta$-CDP. However, the question is whether or not $\beta$-CDP/IBU still has the inclusion ability to form self-assembled hydrogels with HEC- $\mathrm{C}_{12}$. The answer is given by the detection results of the phenolphthalein probe method. Due to the decolorization of purple phenolphthalein upon complexation with $\beta-\mathrm{CD}$ at $\mathrm{pH}=10.5$, the content of active residual cavities in $\beta$-CDP with inclusion abilities in $\beta$-CDP/IBU can be determined.

The calibration curve of active $\beta$-CD is seen in eqn (8), with $R^{2}$ of 0.9990:

$$
\Delta A=9635.7 c_{\mathrm{CD}}+0.00181
$$

where $\Delta A$ denotes the difference between the UV absorbance of a diluted $\beta-C D$ solution and that of a $\beta$-CD blank (phenolphthalein solutions without addition of $\beta-\mathrm{CD}$ ), and $c_{\mathrm{CD}}$ denotes the concentrations of the diluted active $\beta-\mathrm{CD}\left(\mathrm{mol} \mathrm{L}^{-1}\right)$.

The content of active residual cavities in $\beta$-CDP in $\beta$-CDP/IBU is calculated using eqn (9):

Active residual cavities of $\beta$-CDP content $\left(\mathrm{wt}^{\%} \%\right)=\frac{c \times 0.2 \times M}{m}$

where $c$ represents the concentration of active residual cavities in $\beta$-CDP in $\beta$-CDP/IBU $\left(\mathrm{mol} \mathrm{L}^{-1}\right), M$ represents the $\beta$-CD molecular weight of $1135 \mathrm{~g} \mathrm{~mol}^{-1}, m$ denotes the weight of dry $\beta$-CDP/IBU (g), and the factor of 0.2 is a calculation of the volume $(0.005 \mathrm{~L})$ of the extracting solution and the dilution factor (40).

The content of active residual cavities in $\beta$-CDP in $\beta$-CDP/IBU is determined to be $31.3 \mathrm{wt} \%$ by UV spectroscopy after storing overnight, which verifies that $\beta$-CDP/IBU still has the ability to form inclusion complexes with the $\mathrm{C}_{12}$ side-chains on HEC. ${ }^{64}$

\section{Characterization of gel-( $\beta)$ CDP-HEC/IBU}

Dynamic viscosity analysis. Self-assembly of gel-( $\beta) C D P-$ HEC/IBU demands certain concentrations of $\beta$-CDP/IBU and HEC-C $_{12}$. In order to find these critical concentrations, a series of mixtures with $\beta$-CDP/IBU concentrations from $0 \mathrm{mg} \mathrm{mL}^{-1}$ to $55 \mathrm{mg} \mathrm{mL} \mathrm{mL}^{-1}$ and HEC-C ${ }_{12}$ concentrations from $5 \mathrm{mg} \mathrm{mL}^{-1}$ to $40 \mathrm{mg} \mathrm{mL}{ }^{-1}$ were prepared. The $\eta$ values were subsequently recorded.

Dynamic viscosities of gel-( $\beta$ CDP-HEC/IBU at different HEC$\mathrm{C}_{12}$ and $\beta$-CDP/IBU concentrations are shown in Fig. 8. Without the addition of $\beta$-CDP/IBU, as the concentrations of $\mathrm{HEC}_{12}$ are more than $20 \mathrm{mg} \mathrm{mL} \mathrm{m}^{-1}$, the $\eta$ values of the mixtures are significantly increased. This phenomenon can be explained by the thickening effect of HEC. ${ }^{65,66}$ When the concentrations of $\beta$ $\mathrm{CDP} / \mathrm{IBU}$ ranged from $15 \mathrm{mg} \mathrm{mL}^{-1}$ to $55 \mathrm{mg} \mathrm{mL}^{-1}$, the $\eta$ values

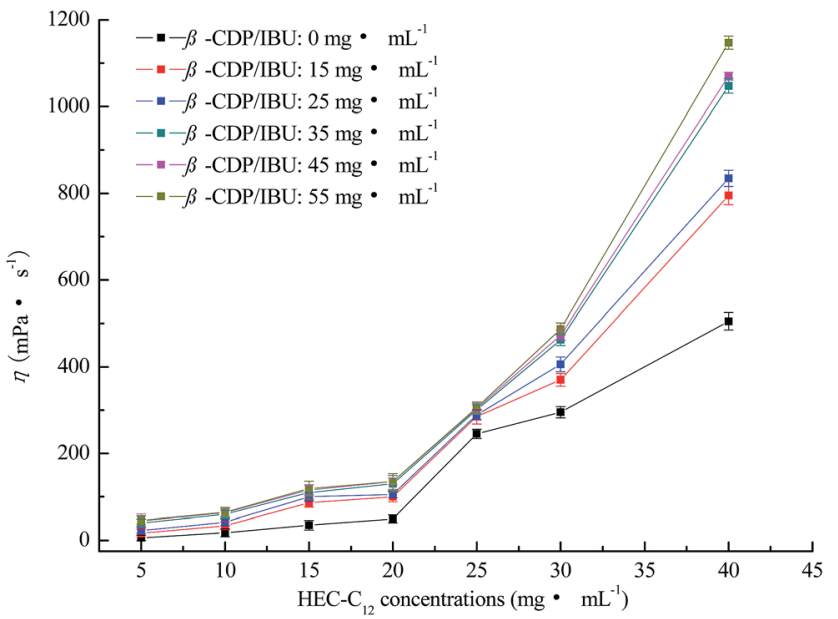

Fig. 8 The dynamic viscosity of gel-( $\beta$ )CDP-HEC at different HEC- $C_{12}$ and $\beta$-CDP concentrations.

of the mixtures changed a lot, especially at concentrations of HEC-C $_{12}$ ranging from $30 \mathrm{mg} \mathrm{mL}^{-1}$ to $40 \mathrm{mg} \mathrm{mL}^{-1}$. It can be inferred that enough hydrophobic $\mathrm{C}_{12}$ side-chains are the requirement for forming hydrogel polymer networks due to $\mathrm{CD}$ inclusion chemistry. When the concentration of HEC- $\mathrm{C}_{12}$ was $30 \mathrm{mg} \mathrm{mL}{ }^{-1}$, the $\eta$ value showed a significant increase compared to that without the addition of $\beta$-CDP/IBU. This result demonstrates that the critical concentration of $\mathrm{HEC}^{-\mathrm{C}_{12}}$ for forming self-assembled hydrogels can be fixed at $30 \mathrm{mg} \mathrm{mL} \mathrm{m}^{-1}$. The self-assembly process is represented in Fig. 9. In Fig. 9, HEC- $\mathrm{C}_{12}$ and $\beta$-CDP are synthesized and IBU is solubilized and encapsulated by $\beta$-CDP. Then $\mathrm{C}_{12}$ side-chains are grafted on HEC to form inclusion complexes with the cavities of $\beta$-CDP in $\beta$-CDP/IBU through host-guest interactions.

From Fig. 8, when the concentration of HEC-C $\mathrm{C}_{12}$ is $30 \mathrm{mg}$ $\mathrm{mL}^{-1}$, the $\eta$ values of the mixtures change a little as the concentrations of $\beta$-CDP/IBU range from $35 \mathrm{mg} \mathrm{mL}^{-1}$ to $55 \mathrm{mg}$ $\mathrm{mL}^{-1}$. It can be inferred that $\mathrm{C}_{12}$ on HEC is encapsulated enough by $35 \mathrm{mg} \mathrm{mL}^{-1}$ of $\beta$-CDP/IBU to form a hydrogel when

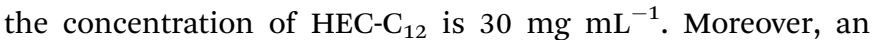
increase in the concentration of $\beta$-CDP/IBU cannot give benefits for the formation of hydrogels, so the critical concentration of $\beta$ -

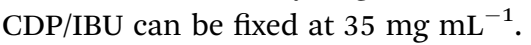

${ }^{1} \mathbf{H}$ NMR analysis. In order to prove the existence of IBU in gel-( $\beta$ CDP-HEC/IBU, ${ }^{1} \mathrm{H}$ NMR spectroscopy of IBU, $\beta$-CDP and gel-( $\beta$ CDP-HEC/IBU was performed and the results are illustrated in Fig. 10a, b and c, respectively. Compared to IBU (Fig. 10a), the ${ }^{1} \mathrm{H}$ NMR spectrum of gel-( $\beta$ )CDP-HEC/IBU in Fig. 10c can clearly show ${ }^{1} \mathrm{H}$ signals at $\delta 0.85 \mathrm{ppm}, 1.35 \mathrm{ppm}$, $2.42 \mathrm{ppm}$, and a double peak at $\delta 7.10 \mathrm{ppm}$ and $7.18 \mathrm{ppm}$, which are attributed to the framework protons of the IBU molecule. Also in Fig. 10c, the framework protons of $\mathrm{HEC}_{12} \mathrm{C}_{12}$ (Fig. 1b) and $\beta$-CDP (Fig. 10b) can be observed. Due to the different solubilities of IBU, HEC-C $\mathrm{C}_{12}$ and $\beta$-CDP in DMSO- $\mathrm{d}_{6}$, the encapsulation efficiency of IBU by gel-( $\beta$ )CDP-HEC/IBU cannot be calculated using the results of ${ }^{1} \mathrm{H}$ NMR spectroscopy. 

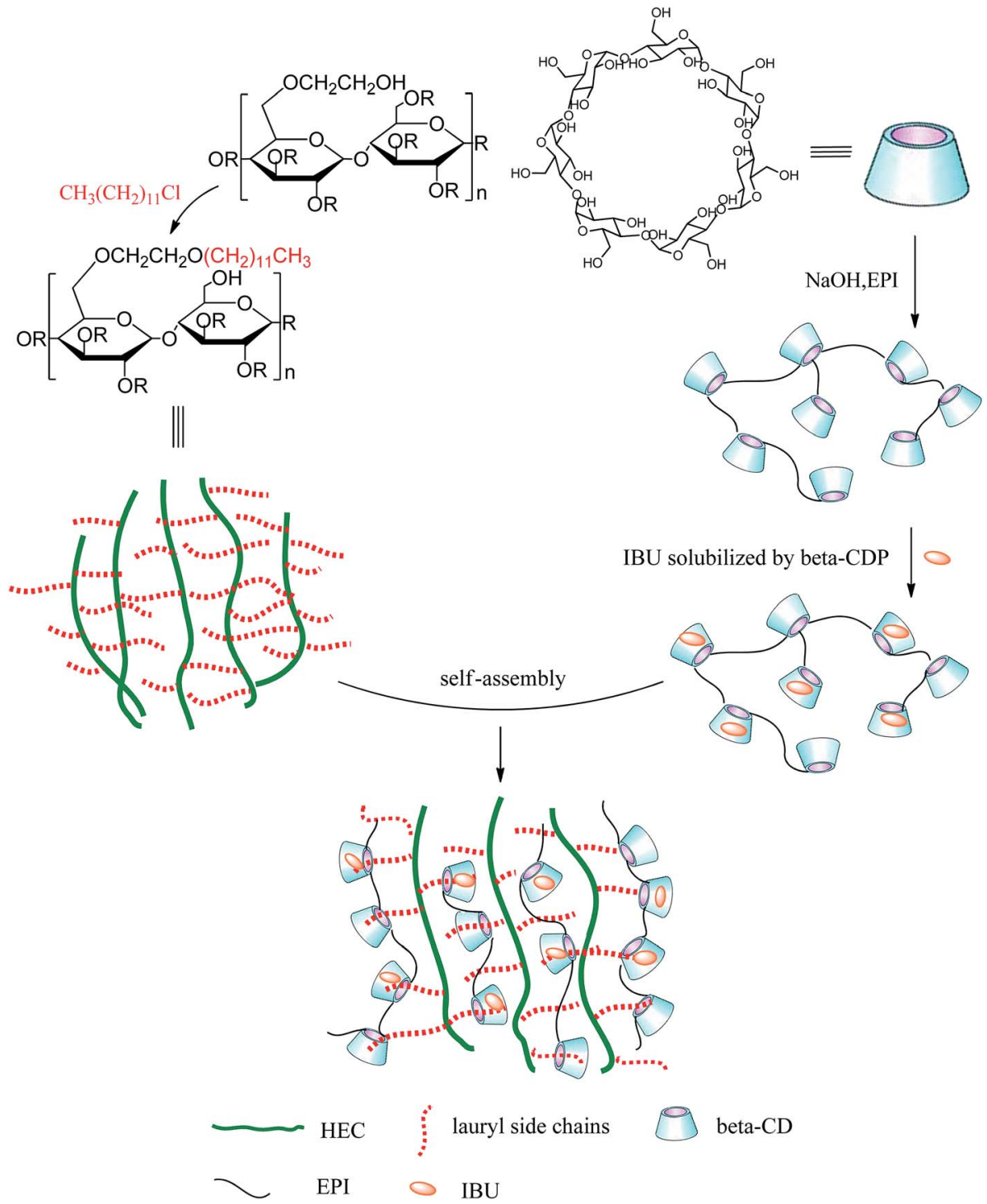

Fig. 9 Schematic representation of the formation of self-assembled hydrogels and their drug-loading pattern.

FTIR analysis. FTIR spectra of IBU and gel-( $\beta) \mathrm{CDP}-\mathrm{HEC} / \mathrm{IBU}$ are shown in Fig. 11a and b, respectively. The band at $1763 \mathrm{~cm}^{-1}$ in Fig. 11a is attributed to the $\mathrm{C}-\mathrm{O}$ groups of IBU, but that in Fig. $11 \mathrm{~b}$ is obviously weakened. This phenomenon demonstrates that IBU is introduced into the synthesized product of gel- $(\beta) \mathrm{CDP}-\mathrm{HEC} / \mathrm{IBU}$ but the loading amount is small. Furthermore, the FTIR spectrum of gel-( $\beta$ )CDP-HEC/IBU (Fig. 11b) has the characteristic infrared peaks of $\mathrm{HEC}_{12}$ (Fig. $2 \mathrm{~b}$ ) and $\beta$-CDP (Fig. 5b), this result probably proves that such a method for the synthesis of gel-( $\beta)$ CDP-HEC/IBU is feasible.

SEM analysis. With the addition of IBU, the SEM morphology of $\beta$-CDP/IBU (Fig. 3f) shows a sparse surface with irregular colloidal thin slices on the sides. The morphology of gel-( $\beta) \mathrm{CDP}$ HEC/IBU (Fig. 3g) demonstrates a fluffy debris on the sides and the surface of gel-( $\beta$ )CDP-HEC/IBU is as compact as that of HEC$\mathrm{C}_{12}$ (Fig. 3b). Both the two "new substances" show a homogenous amorphous structure with a complete absence of the characteristic plate shaped crystals of IBU (Fig. 3e). This change in the native morphology is suggestive of a possible interaction between IBU and $\beta$-CDP in gel-( $\beta$ )CDP-HEC/IBU.

PXRD analysis. From PXRD of the samples (Fig. 12), the diffractogram of IBU (Fig. 12a) can be seen to show typical sharp peaks at $6.10^{\circ}, 16.67^{\circ}$, and $22.32^{\circ}$ and several minor peaks on the $2 \theta$ scale, while those patterns of $\beta$-CDP/IBU (Fig. 12b) and gel-( $\beta$ )CDP-HEC/IBU (Fig. 12c) don't show any sharp peaks, which confirms their amorphous nature. In addition, new peaks are observed at $11.82^{\circ}$ and $18.65^{\circ}$ in Fig. $12 \mathrm{~b}$ and at $11.30^{\circ}$ and $18.89^{\circ}$ in Fig. 12c, which suggests host-guest interactions between $\beta$-CDP and IBU in $\beta$-CDP/IBU and gel-( $\beta$ )CDP-HEC/IBU. This result is in-line with the results of the ${ }^{1} \mathrm{H}$ NMR and FTIR spectroscopy and the SEM studies.

\section{Loading content of IBU in gel-( $\beta)$ CDP-HEC/IBU}

As mentioned above, $1.50 \mathrm{~g}$ of $\beta$-CDP was used to solubilize $0.17 \mathrm{~g}$ of IBU for the synthesis of $\beta-\mathrm{CDP} / \mathrm{IBU}$, and the 
(a)IBU (b) $\beta-\mathrm{CDP}$

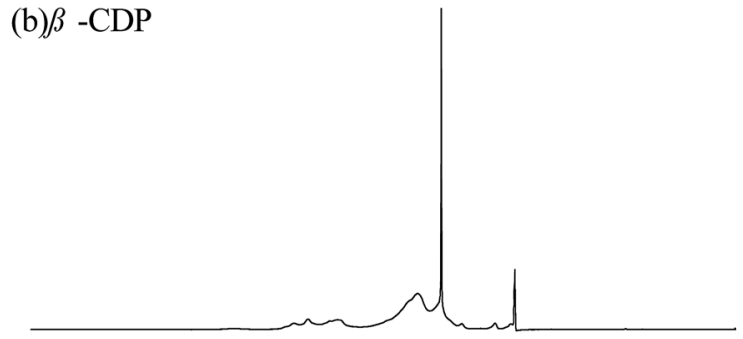

(c)gel-( $\beta$ )CDP-HEC/IBU

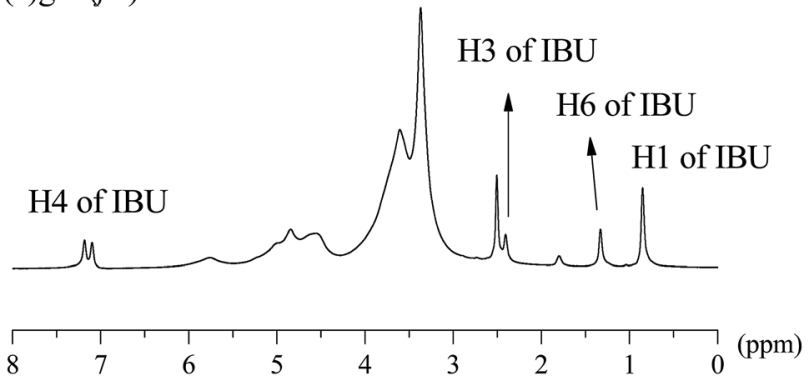

Fig. $10{ }^{1} \mathrm{H}$ NMR spectra of IBU (a), $\beta$-CDP (b) and gel-( $\beta$ )CDP-HEC/ IBU (c) at $400 \mathrm{MHz}$ in DMSO- $d_{6}$ at room temperature.

concentrations of $\beta$-CDP/IBU and HEC- $\mathrm{C}_{12}$ were fixed at $35 \mathrm{mg}$ $\mathrm{mL}^{-1}$ and $30 \mathrm{mg} \mathrm{mL}^{-1}$ for preparation of gel-( $\left.\beta\right) \mathrm{CDP}-\mathrm{HEC} / \mathrm{IBU}$, respectively. So the content of IBU loaded in gel-( $\beta)$ CDP-HEC/ IBU can be calculated using eqn (10):

$$
\text { IBU loading content }(\%)=\frac{\frac{0.17}{1.5+0.17} \times c_{\beta-\mathrm{CDP} / \mathrm{IBU}} \times v}{c_{\beta-\mathrm{CDP} / \mathrm{IBU}} v+c_{\mathrm{HEC}-\mathrm{C}_{12}} v}
$$

where $c_{\beta-\mathrm{CDP} / \mathrm{IBU}}$ and $c_{\mathrm{HEC}-\mathrm{C}_{12}}$ represent the concentrations of $\beta$ $\mathrm{CDP} / \mathrm{IBU}$ and $\mathrm{HEC}-\mathrm{C}_{12}$ needed to form gel-( $\left.\beta\right) \mathrm{CDP}-\mathrm{HEC} / \mathrm{IBU}$ $\left(\mathrm{mol} \mathrm{L}^{-1}\right)$, respectively, and $v$ denotes the volume of distilled water needed to form gel-( $\beta$ )CDP-HEC/IBU (mL).

The content of IBU loaded in gel-( $\beta)$ CDP-HEC/IBU was calculated as $5 \mathrm{wt} \%$ according to the equation above.

\section{Swelling and in vitro release characteristics of IBU from gel-( $(\beta)$ CDP-HEC/IBU}

The swelling of hydrogels has a great effect on the rate of drug release. Diffusion-controlled drug release increases with an increase in the swelling of the hydrogel. ${ }^{67}$ Therefore, in order to better understand the IBU release mechanism, the swelling characteristics of gel-( $\beta$ )CDP-HEC/IBU were investigated. The swelling profile at different time intervals is shown in Fig. 13. From the graph it can be seen that the values of SR for gel- $(\beta)$

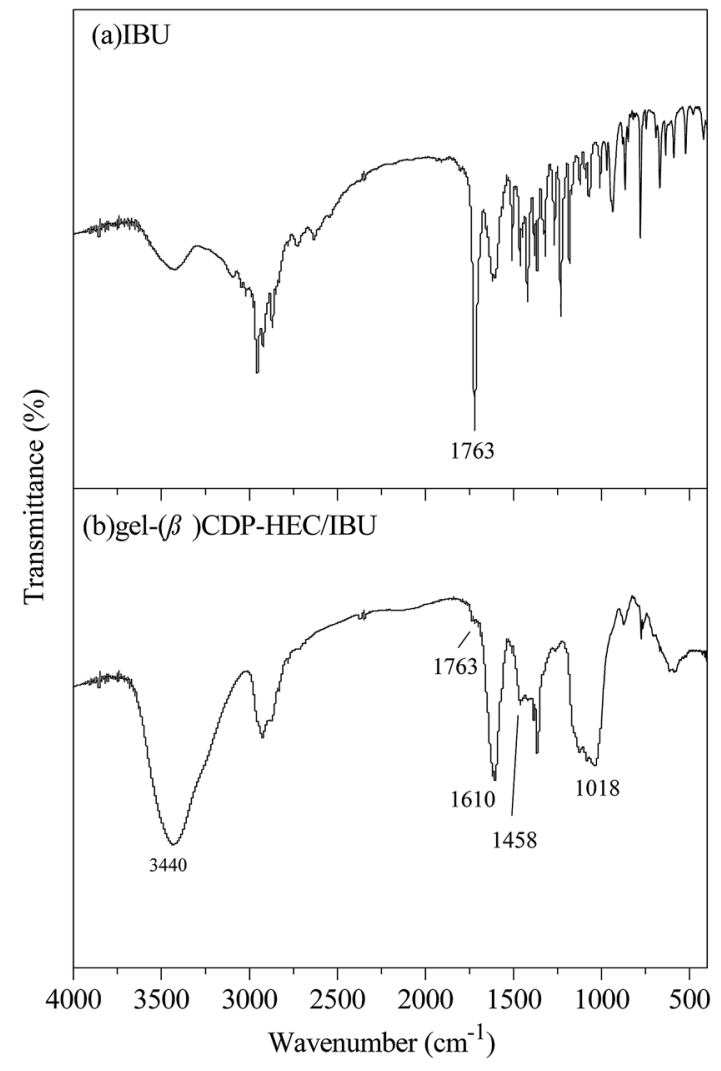

Fig. 11 FTIR spectra of IBU (a) and gel-( $\beta) C D P-H E C / I B U(b)$.

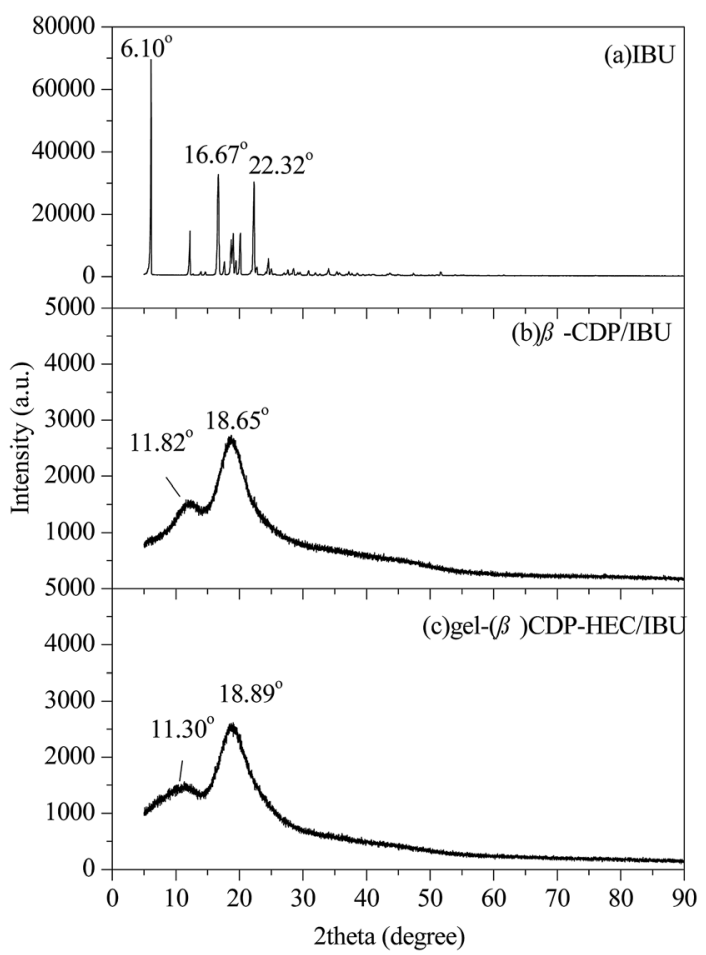

Fig. 12 PXRD spectra of IBU (a), $\beta$-CDP/IBU (b) and gel-( $\beta) C D P-H E C /$ IBU (c). 


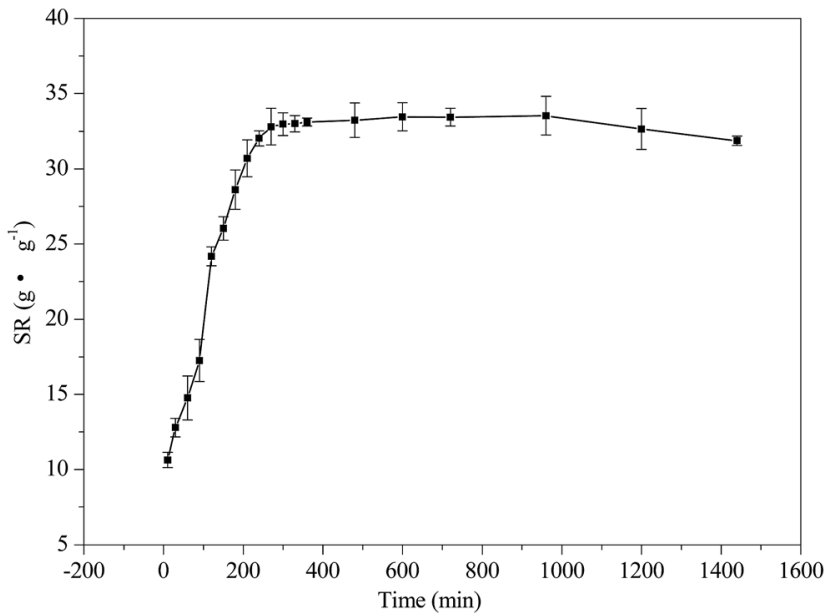

Fig. 13 The swelling ratio of gel-( $\beta$ CDP-HEC/IBU at different time intervals.

CDP-HEC/IBU increase with time in the first 270 min. A sharp increase in this initial state is due to the diffusion of water molecules into the hydrogel network and polymer expansion. From 270 min to $960 \mathrm{~min}$, the values of SR plateau due to the water molecules reaching equilibrium in gel-( $\beta$ CDP-HEC/IBU. After $960 \mathrm{~min}$, the SR values decrease with time, this phenomenon may be attributed to the fact that the matrices of gel- $(\beta)$ CDP-HEC/IBU have degraded in the PBS buffer solution after the long duration.

In vitro release characteristics of IBU in gel-( $\beta$ )CDP-HEC/IBU were investigated. The released IBU content can be detected by a UV spectrophotometer (TU1901, Persee, China) at a wavelength of $219 \mathrm{~nm}$ according to the calibration curve of IBU as described above and the IBU cumulative release efficiency $(R$, $\mathrm{wt} \%)$ was calculated using eqn (11). ${ }^{68,69}$

$$
R=
$$

Cumulative release amount of IBU after prescribed time

$$
\text { Initial amount of IBU }
$$

$\times 100 \%$

As a control group, the release characteristics of HEC-C $\mathrm{C}_{12} /$ IBU were also studied in order to evaluate the role of $\beta$-CDP in the hydrogels for the sustained release of IBU. The release profile is presented in Fig. 14. Most IBU molecules (91.5 wt\%) were released quickly from $\mathrm{HEC}-\mathrm{C}_{12} / \mathrm{IBU}$ within $240 \mathrm{~min}$, while gel-( $\beta$ CDP-HEC/IBU presented a significant sustained release of IBU over 1440 min through the dialysis bag. In combination with the results of the swelling characteristics, the release of IBU in the first 960 min can be attributed to IBU molecules escaping from the cavities of $\beta$-CDP in gel-( $\beta$ )CDP-HEC/IBU. From $960 \mathrm{~min}$ to $1440 \mathrm{~min}$, IBU is probably released through the degradation of gel-( $\beta$ )CDP-HEC/IBU matrices in the buffer solution. This phenomenon demonstrates that IBU encapsulated in the cavities of $\beta$-CDP in gel-( $\beta$ )CDP-HEC/IBU can be released through a long-term mechanism. ${ }^{70}$

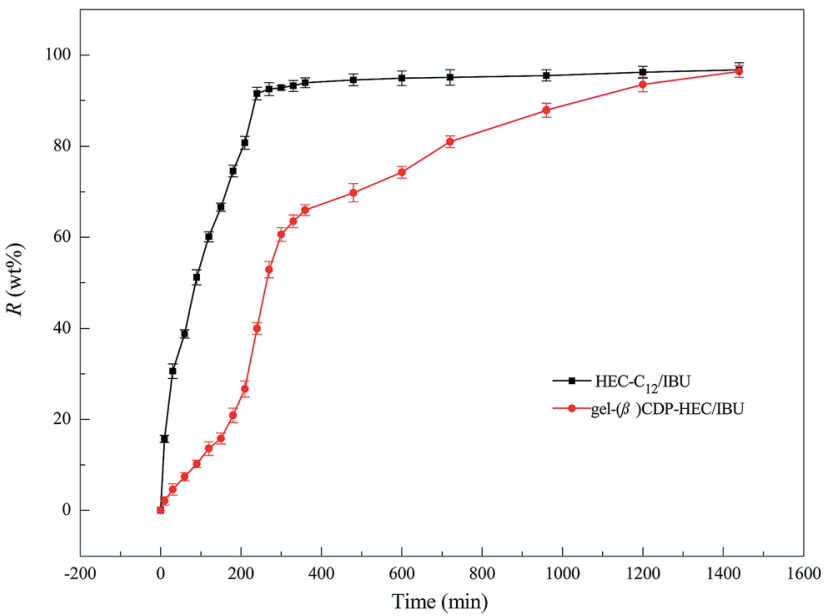

Fig. 14 The release profile of IBU in gel-( $\beta) C D P-H E C / I B U$ and HEC$\mathrm{C}_{12} / \mathrm{IBU}$.

In addition, in order to determine the IBU release kinetic model describing the release mechanism, Origin 8.0 software was used. ANOVA analysis and the kinetic parameters for the different kinetic models were determined by linear and nonlinear curve fittings and the results are summarized in Table 1. From Table 1, the ANOVA results "Prob $>F$ " for the four kinetic models are all far lower than 0.05 , and it can be concluded that all the fitted curves in the experimental design are statistically significant at a $95 \%$ confidence level. Moreover, the value of the correction coefficient $R^{2}$ for the Korsmeyer and Peppas kinetic model is extremely high (>0.99), greater than those of the zero order, first order and Higuchi models. Hence, the kinetic model of Korsmeyer and Peppas gives better correlation for the release of IBU from gel-( $\beta$ CDP-HEC/IBU. Furthermore, the diffusion exponent " $n$ " was calculated as 0.8731 , which is between 0.5 and 1 , so the release procedure is a non-Fickian diffusion process. Such results indicate that after

Table 1 Parameters of the four kinetic models

\begin{tabular}{lll}
\hline Kinetic model & & Parameters \\
\hline Zero order & Fitted curve & $\frac{M_{t}}{M_{\infty}}=0.0007 t+0.1598$ \\
& $R^{2}$ & 0.7818 \\
& Prob $>F$ & $2.32112 \times 10^{-7}$ \\
First order & Fitted curve & $\ln \left(1-\frac{M_{t}}{M_{\infty}}\right)=-0.0023 t+0.0134$ \\
& & 0.9803 \\
& $R^{2}$ & $1.1102 \times 10^{-16}$ \\
Higuchi & Prob $>F$ & $\frac{M_{t}}{M_{\infty}}=0.0315 t^{\frac{1}{2}}-0.0927$ \\
& Fitted curve & 0.9046 \\
Korsmeyer and & Fitted curve & $1.2638 \times 10^{-10}$ \\
Peppas & $R_{t}^{2}$ & $\frac{M_{t}}{M_{\infty}}=0.0027 t^{0.8731}$ \\
& $R^{2}$ & 0.9978 \\
& Prob $>F$ & $1.0958 \times 10^{-16}$
\end{tabular}


swelling, IBU release occurs through the combination of both diffusion and erosion of gel-( $\beta$ )CDP-HEC/IBU.

\section{Conclusions}

A novel self-assembled, drug loaded gel-( $\beta$ )CDP-HEC/IBU was synthesized through host-guest interactions. Hydrophobic IBU molecules were solubilized and encapsulated by $\beta$-CDP and the content of residual cavities in $\beta$-CDP with inclusion abilities in $\beta$-CDP/IBU was determined to be $31.3 \mathrm{wt} \%$. In the hydrogel selfassembly process, the residual cavities provided binding sites for associating with $\mathrm{HEC}-\mathrm{C}_{12}$ and the hydrogel demonstrates a high viscosity when the concentrations of HEC- $\mathrm{C}_{12}$ and $\beta-\mathrm{CDP} /$ IBU are fixed at $30 \mathrm{mg} \mathrm{mL} \mathrm{m}^{-1}$ and $35 \mathrm{mg} \mathrm{mL} \mathrm{m}^{-1}$, respectively. Moreover, the encapsulated IBU content in gel-( $\beta)$ CDP-HEC/IBU was detected as $5 \mathrm{wt} \%$, and gel- $(\beta) \mathrm{CDP}-\mathrm{HEC} / \mathrm{IBU}$ presents the significant sustained release of IBU over $1440 \mathrm{~min}$, for which gel-( $\beta)$ CDP-HEC/IBU has potential application value in restraining soft-tissue pain and osteoarthritis. In addition, after swelling, the release of IBU from gel-( $\beta$ )CDP-HEC/IBU complies with the Korsmeyer and Peppas kinetic model and is a nonFickian diffusion process; in that case, the release mechanism is the synergistic effect of erosion and dissolution of the gel- $(\beta)$ CDP-HEC/IBU matrix.

\section{Acknowledgements}

This study is supported by Fundamental Research Funds for the Central Universities (DL13EA02), and the National Natural Science Fund of China (NSFC, 51403030). The China Postdoctoral Science Foundation (2012M520696) and Heilongjiang Postdoctoral Grant (LBH-Z12009) are also gratefully acknowledged for support.

\section{References}

1 X. Zheng, Q. Zhang, J. Liu, Y. Pei and K. Tang, RSC Adv., 2016, 6, 71999-72007.

2 H. Luo, G. Xiong, Z. Yang, S. R. Raman, H. Si and Y. Wan, RSC Adv., 2014, 4, 14369-14372.

3 J. Kim, B. Wu, S. M. Niedzielski, M. T. Hill, R. M. Coleman, A. Ono and A. Shikanov, J. Biomed. Mater. Res., Part A, 2015, 103, 2701-2710.

4 E. A. Appel, J. D. Barrio, X. J. Loh and O. A. Scherman, Chem. Soc. Rev., 2012, 41, 6195-6214.

5 C. Fu, X. Lin, J. Wang, X. Zheng, X. Li, Z. Lin and G. Lin, J. Mater. Sci.: Mater. Med., 2016, 27, 1-7.

6 S. K. H. Gulrez, S. Al-Assaf and G. O. Phillips, Prog. Mol. Environ. Bioeng.: Anal. Model. Technol. Appl., 2011, 664-677, DOI: $10.5772 / 24553$.

7 N. Mohammed, N. Grishkewich, R. M. Berry and K. C. Tam, Cellulose, 2015, 22, 1-14.

8 J. Yang, S. Han, L. Yang and H. Zheng, J. Chem. Technol. Biotechnol., 2014, 91, 618-623.

9 Q. Yan, Y. Lin, S. Zhang and J. Huang, Chemistry, 2011, 17, 5180-5187.
10 Z. Zhang, R. Zhang, L. Zou and D. J. Mcclements, Food Hydrocolloids, 2016, 58, 160-170.

11 S. Ishiwata and M. Kamiya, Chemosphere, 1999, 38, 22192226.

12 P. Lu, F. Wu and N. Deng, Appl. Catal., B, 2004, 53, 87-93.

13 P. Velusamy, S. Pitchaimuthu, S. Rajalakshmi and N. Kannan, J. Adv. Res., 2014, 5, 19-25.

14 J. C. M. Uitdehaag, d. V. B. A. Van, L. Dijkhuizen, R. Elber and B. W. Dijkstra, Proteins, 2001, 43, 327-335.

15 D. C. Bibby, N. M. Davies and I. G. Tucker, Int. J. Pharm., 2000, 197, 1-11.

16 Y. Liu, X. Fan, T. Kang and L. Sun, Macromol. Rapid Commun., 2004, 25, 1912-1916.

17 H. Zhou, Z. Wang, X. Duan, L. Jiang, P. Cao and J. Li, Biochem. Eng. J., 2016, 111, 100-107.

18 X. Wang, H. Hu, W. Wang, K. I. Lee, C. Gao, L. He, F. Wang, C. Lai, B. Fei and J. H. Xin, Colloids Surf., B, 2016, 143, 342351.

19 M. Wang, J. Wang, Y. Wang, C. Liu, J. Liu, Z. Qiu, Y. Xu and S. F. Lincoln, Colloid Polym. Sci., 2016, 294, 1087-1095.

20 X. Cheng, J. Yong, T. Sun, R. Qi, H. Li and W. Fan, Colloids Surf., B, 2016, 141, 44-52.

21 J. Shen, X. Xin, T. Liu, L. Tong, G. Xu and S. Yuan, J. Colloid Interface Sci., 2016, 468, 78-85.

22 R. Gref, C. Amiel, K. Molinard, S. Daoud-Mahammed, B. Sébille, B. Gillet, J. C. Beloeil, C. Ringard, V. Rosilio, J. Poupaert and P. Couvreur, J. Controlled Release, 2006, 111, 316-324.

23 I. Tomatsu, A. Hashidzume and A. Harada, Macromol. Rapid Commun., 2005, 26, 825-829.

24 S. Tan, L. Katharina, Q. Fu, A. Blencowe and G. G. Qiao, Macromol. Rapid Commun., 2014, 35, 1166-1184.

25 S. Tan, Q. Fu, J. M. P. Scofield, J. Kim, P. A. Gurr, K. Ladewig, A. Blencowe and G. G. Qiao, J. Mater. Chem. A, 2015, 3, 14876-14886.

26 R. Li, X. Zhang, Q. Zhang, H. Liu, J. Rong, M. Tu, R. Zeng and J. Zhao, J. Appl. Polym. Sci., 2015, 133.

27 M. U. Minhas, M. Ahmad, S. Khan, D. L. Ali and M. Sohail, Cellul. Chem. Technol., 2016, 50, 233-242.

28 K. Yang, S. Wan, B. Chen, W. Gao, J. Chen, M. Liu, B. He and H. Wu, Carbohydr. Polym., 2016, 136, 300-306.

29 Y. Ye and X. Hu, J. Nanomater., 2016, 2016, 1-8.

30 H. Yamaguchi, Y. Kobayashi, R. Kobayashi, Y. Takashima, A. Hashidzume and A. Harada, Nat. Commun., 2012, 3, 19596-19600.

31 M. Nakahata, Y. Takashima and A. Harada, Macromol. Rapid Commun., 2015, 37, 86-92.

32 Z. R. Miladinovic, M. Micic and E. Suljovrujic, J. Polym. Res., 2016, 23, 1-12.

33 Z. Liu and H. Huang, Carbohydr. Polym., 2016, 147, 226-233. 34 J. K. Pandey, S. H. Ahn, C. S. Lee, A. K. Mohanty and M. Misra, Macromol. Mater. Eng., 2010, 295, 975-989.

35 L. Altomare, A. Cochis, A. Carletta, L. Rimondini and S. Farè, J. Mater. Sci.: Mater. Med., 2016, 27, 1-13.

36 H. Chen, X. Chang, D. Du, J. Li, H. Xu and X. Yang, Int. J. Pharm., 2006, 315, 52-58. 
37 H. Chen, D. Mou, D. Du, X. Chang, D. Zhu, J. Liu, H. Xu and X. Yang, Int. J. Pharm., 2007, 341, 78-84.

38 L. Djekic, M. Martinovic, R. Stepanović-Petrović, A. Micov, M. Tomić and M. Primorac, Eur. J. Pharm. Sci., 2016, 92, 255-265.

39 R. Ray, S. Maity, S. Mandal, T. K. Chatterjee and B. Sa, Adv. Polym. Technol., 2011, 30, 1-11.

40 M. Maswal, O. A. Chat and A. A. Dar, Colloid Polym. Sci., 2015, 293, 1723-1735.

41 J. Szeman, E. Fenyvesi, J. Szejtli, H. Ueda, Y. Machida and T. Nagai, J. Inclusion Phenom. Macrocyclic Chem., 1987, 5, 427-431.

42 E. Renard, A. Deratani, G. Volet and B. Sebille, Eur. Polym. J., 1997, 33, 49-57.

43 C. Koopmans and H. Ritter, Macromolecules, 2008, 41, 74187422.

44 M. F. Oliveira, D. Suarez, J. C. B. Rocha, M. E. Cortés, F. B. D. Sousa and R. D. Sinisterra, Mater. Sci. Eng., C, 2015, 54, 252-261.

45 T. Higuchi and K. A. Connors, Adv. Anal. Chem. Instrum., 1965, 4, 117-212.

46 A. Heydari, M. Iranmanesh, F. Doostan and H. Sheibani, Pharm. Chem. J., 2015, 49, 605-612.

47 T. Wang, B. Li, H. Si and L. Lin, Surf. Interface Anal., 2011, 43, 1532-1538.

48 H. Si, B. Li, T. Wang and Z. Xu, Wood Sci. Technol., 2013, 47, 601-613.

49 R. Li, X. Zhang, Q. Zhang, H. Liu, J. Rong, M. Tu, R. Zeng and J. Zhao, J. Appl. Polym. Sci., 2015, 133, 43072.

50 S. K. H. Gulrez, S. Al-Assaf and G. O. Phillips, Hydrogels: Methods of preparation, characterisation and applications, in Molecular and Environmental Bioengineering, Assaf, South Africa, 2010.

51 P. Ji, T. Yu, Y. Liu, J. Jiang, J. Xu, Y. Zhao, Y. Hao, Y. Qiu, W. Zhao and C. Wu, Drug Des., Dev. Ther., 2016, 10, 911-925.

52 M. Halayqa and U. Domańska, Int. J. Mol. Sci., 2014, 15, 23909-23923.
53 M. C. Fontana, T. L. Durli, A. R. Pohlmann, S. S. Guterres and R. C. R. Beck, Powder Technol., 2014, 258, 49-59.

54 C. Y. Hsu, T. Sato, S. Moriyama and M. Higuchi, Eur. Polym. J., 2016, 83, 499-506.

55 A. B. Morales-Cepeda, C. A. Castillo-Miranda, C. F. CastroGuerrero, H. Salas-Papayanopolos, H. A. Ocejo-Velasco, J. A. González-Sánchez, U. Paramo and H. D. Alva-Salazar, Int. J. Polym. Sci., 2016, 2634104.

56 N. A. Peppas and R. W. Korsmeyer, Hydrogels in Med. Pharm., vol. III. Prop. Appl., 1987, vol. 3, pp. 109-136.

57 P. L. Ritger and N. A. Peppas, J. Controlled Release, 1987, 5, 23-36.

58 T. J. Higuchi, J. Pharm. Sci., 1963, 52, 1145-1149.

59 R. W. Korsmeyer, R. Gurny, E. Doelker, P. Buri and N. A. Peppas, Int. J. Pharm., 1983, 15, 25-35.

60 N. A. Peppas, Pharm. Acta Helv., 1985, 60, 110-111.

61 A. K. Bajpai, S. K. Shukla, S. Bhanu and S. Kankane, Prog. Polym. Sci., 2008, 33, 1088-1118.

62 Y. Liao, X. Zhang, C. Li, Y. Huang, M. Lei, M. Yan, Y. Zhou and C. Zhao, Carbohydr. Polym., 2016, 147, 415-425.

63 W. Sangpheak, J. Kicuntod, R. Schuster, T. Rungrotmongkol, P. Wolschann, N. Kungwan, H. Viernstein, M. Mueller and P. Pongsawasdi, Beilstein J. Org. Chem., 2015, 11, 2763-2773.

64 N. Sun, T. Wang and C. Liu, Wood Sci. Technol., 2016, 50, 1243-1260.

65 W. Sun, D. Sun, Y. Wei, S. Liu and S. Zhang, J. Colloid Interface Sci., 2007, 311, 228-236.

66 G. Zhao and S. B. Chen, J. Colloid Interface Sci., 2007, 316, 858-866.

67 T. S. Anirudhan, Binusreejayan and J. R. Deepa, J. Appl. Polym. Sci., 2016, 133, 43479.

68 T. Wang, B. Li, H. Si, L. Lin and L. Chen, J. Inclusion Phenom. Macrocyclic Chem., 2011, 71, 207-213.

69 W. Hao, T. Xia, Y. Shang, S. Xu and H. Liu, Colloid Polym. Sci., 2016, 294, 1107-1116.

70 B. Mandal, D. Das, A. P. Rameshbabu, S. Dhara and S. Pal, RSC Adv., 2016, 6, 19605-19611. 